\title{
Chemically Assisted Primary Sedimentation as a tool to improve energy balance of a large wastewater treatment plant
}

\author{
Mateusz Muszyński-Huhajło ${ }^{1, *}$, Stanisław Miodoński ${ }^{1}$, and Katarzyna Rucka $^{1}$ \\ ${ }^{1}$ Faculty of Environmental Engineering, Wroclaw University of Science and Technology, \\ Plac Grunwaldzki 9, 50-377 Wroclaw, Poland
}

\begin{abstract}
Chemicals addition at the mechanical part of wastewater treatment plant can improve overall treatment efficiency and help in solving some plant's operational problems. Application of such process in the primary clarifiers, named as Chemically Assisted Primary Sedimentation, can also be a huge step towards energy balance improvement for the whole plant. Use of relatively cheap coagulants, such as ferric or alum salts can be an easy way to increase treatment efficiency significantly, as coagulation and flocculation intensifies followed by chemical precipitation. Additional removal of soluble pollutants and suspended solids increases their load in the primary sludge, avoiding their potential removal in the biological part of the plant. Additional organic matter in the primary sludge allows to produce more gas in the anaerobic digestion process and thus increase energy production by the CHP units. Efficiency of different coagulation agents (PIX 109 and PAX XL3) supported by polymer addition was investigated using real municipal wastewater collected from a large Polish wastewater treatment plant (over 500000 p.e.) in a series of lab-scale tests. Proper selection of coagulant and potential polymer dosage has a serious impact on the overall costs of this additional treatment and energy balance. Based on obtained results, economic analysis was performed for the same plant to evaluate potential gains and losses of implementing such practice.
\end{abstract}

\section{Introduction}

Nowadays, optimization of wastewater treatment plants (WWTPs) is a necessary effort to improve their energy balance without affecting the overall treatment efficiency. Recent development of sidestream treatment technologies resulted in number of full-scale implementations. Such upgrade of the WWTP technological system creates further potential of mainstream treatment optimization as its load is reduced due to efficient sidestream treatment. Ammonium load, as the main pollutant present in the reject water from digested sludge dewatering, can reach even $25 \%$ of the whole plant's daily N-load [1], what makes efficient sidestream removal crucial for nitrification-denitrification performance in the

\footnotetext{
*Corresponding author: mateusz.muszynski-huhajlo@pwr.edu.pl
} 
mainstream reactor. Discovery and development of deammonification process (i.e. partial nitritation-Anammox, DEAMON, CANON technologies [2-4]) in the past two decades create great opportunity for completely autotrophic ammonium removal from reject water stream [5]. Popularity of this solution can be easily measured by the number of full-scale implementations however, information about the impact of such upgrade on the mainstream reactor operation regime is still limited.

\subsection{Aim of this study}

After decrease in nitrogen load directed to mainstream reactor due to sidestream deammonification, denitrification requirements for organic matter are lower what creates opportunity for increase its load directed to digestion process. This study presents experimental verification of CAPS efficiency by using two types of coagulants with or without additional polyelectrolyte dosage. Experimental results were used for further economical calculations of such action.

\section{Materials and methods}

\subsection{Medium characteristics}

Real municipal wastewater after a preliminary treatment from a large WWTP (> 500000 p.e.) were used in this study. The preliminary treatment consisted of screening and particles sedimentation in grit removal chamber. A single wastewater sample was collected directly from a primary clarifier influent and used for all performed tests. For medium characteristics see section 3 .

\subsection{Analytical methods}

Collected samples were filtered with syringe filters, pore size $1.0 \mu \mathrm{m}$ and after that total, ammonium, nitrite, nitrate nitrogen, total phosphorus/phosphates concentrations were measured using Hach photometric cuvette tests: LCK338 (range 20-100 mg N $\mathrm{Not}_{\text {tot }} / \mathrm{dm}^{3}$ ), LCK303 (range 2-47 mg N-NH ${ }_{4}^{+} / \mathrm{dm}^{3}$ ), LCK342 (range 0.6-6 mg N-NO ${ }_{2}{ }^{-} / \mathrm{dm}^{3}$ ), LCK340 (range 5-35 mg N-NO ${ }_{3}^{-} / \mathrm{dm}^{3}$ ), LCK348 (range 0.5-5 mg P-PO $4 / \mathrm{dm}^{3}$ ) and a DR3900 spectrophotometer. Chemical Oxygen Demand (COD) was determined using closed reflux colorimetric method in three types of samples: without filtering, after $1.0 \mu \mathrm{m}$ filter for suspended solids removal and after $0.1 \mu \mathrm{m}$ filter for further colloids removal. Alkalinity was measured using bromocresol green/methyl red as indicator. Total suspended solids (TSS) and volatile suspended solids (VSS) concentrations were determined using direct weight method according to Standard Methods guideline. For $\mathrm{pH}$ measurements, an EPS-1 electrode (Elmetron) was used.

\subsection{Experiment procedure}

Series of jar tests was performed to investigate organic compounds removal efficiency and primary sedimentation process supported by addition of selected coagulants. Additionally, an impact of potential support of organic polymer on the same coagulants was investigated. The same procedure was used for all the tests: after chemicals addition phase of rapid mixing (2 minutes, 150-180 rpm) followed by slow mixing (18 minutes, 6-10 rpm). After coagulation and flocculation, the mixed liquor was transferred to Imhoff cone for further sedimentation process observations for 120 minutes. Coagulant doses used in each test series 
are summarized in Table1. In the test with additional polyelectrolyte support (Series III and IV) after coagulant addition, $1 \mathrm{mg} / \mathrm{dm}^{3}$ dose of Zetag9048FS was added.

Table 1. Coagulant and polyelectrolyte doses in each test series.

\begin{tabular}{|c|c|c|c|c|c|}
\hline Sample & Dose & Series I & Series II & Series III & Series IV \\
\hline - & $\mathrm{mg} / \mathrm{dm}^{3}$ & - & - & - & - \\
\hline S10 & 10 & \multirow{6}{*}{$\mathrm{FeCL}_{3}-\mathrm{PIX} 109$} & \multirow{6}{*}{$\mathrm{AlCl}_{3}-\mathrm{PAX}$ XL3 } & \multirow{6}{*}{$\begin{array}{l}\mathrm{FeCL}_{3}-\mathrm{PIX} 109 \\
\text { +polyelectrolyte }\end{array}$} & \multirow{6}{*}{$\begin{array}{c}\mathrm{AlCl}_{3}-\mathrm{PAX} \text { XL3 } \\
\text { +polyelectrolyte }\end{array}$} \\
\hline S20 & 20 & & & & \\
\hline S40 & 40 & & & & \\
\hline S60 & 60 & & & & \\
\hline S80 & 80 & & & & \\
\hline S100 & 100 & & & & \\
\hline
\end{tabular}

\subsection{Costs calculations}

Part of this study was also an economical evaluation of potential additional chemical treatment use for improved organic compounds removal. Table 2 summarizes unit costs for each chemical agent used in this experiment, sludge disposal costs and potential income due to improved biogas production and lower oxygen requirements. Unit costs values were mainly selected based on real data acquired from the same WWTP as wastewater used in the experimental part, unless other information stated.

Table 2. Unit costs/earnings values used in performed calculations.

\begin{tabular}{|c|c|c|c|}
\hline Name & Unit & Price & Source \\
\hline \multicolumn{4}{|c|}{ costs } \\
\hline $\mathrm{FeCL}_{3}-$ PIX109 & $€ / \mathrm{kgFe}^{3+}$ & 0.71 & WWTP information \\
\hline $\mathrm{AlCl}_{3}-$ PAX XL3 & $€ / \mathrm{kgAl}^{3+}$ & 1.82 & market price \\
\hline Polyelectrolyte - Zetag9048FS & $€ / \mathrm{kg}_{\text {active substance }}$ & 0.99 & WWTP information \\
\hline Sludge disposal & $€ / \mathrm{kg}$-TSS & 0.1 & WWTP information \\
\hline \multicolumn{5}{|c|}{ earnings } \\
\hline Renewable energy & $€ / \mathrm{m}^{3}$ biogas & 0.21 & own calculation \\
\hline Air demand reduction & $€ / \mathrm{kgCD}_{\text {reduction }}$ & 0.07 & own calculation \\
\hline
\end{tabular}

\section{Results}

Composition of wastewater sample collected from the primary clarifier influent was determined and is presented in Table 3. A single test was performed to determine effect of selected pollutants removal after 2 hours of sedimentation in an Imhoff cone. Results (Table 3) were typical for this process efficiency achieved in municipal wastewater treatment [6].

In further series, coagulation and sedimentation process efficiency was investigated. Selected chemicals, PIX109 or PAX XL3 with or without polymer addition, were tested by using doses in range $10-100 \mathrm{mg} / \mathrm{dm}^{3}$ and COD removal efficiency changes were the main parameter of performed assessment. As expected, higher doses of chemicals resulted in higher COD removal efficiency (Figure 1), achieving, in all series, over $40 \%$ higher effect than conventional sedimentation at dose $80 \mathrm{mg} / \mathrm{dm}^{3}$. Even at smallest doses of chemicals used in this test $\left(10 \mathrm{mg} / \mathrm{dm}^{3}\right)$, at least $22 \%$ higher efficiency could be noticed compared to series without coagulants.

Surprisingly, comparing effects of polyelectrolyte addition on CAPS efficiency only little impact on higher COD removal has been noticed for higher doses of $\mathrm{AlCl}_{3}$ (over $60 \mathrm{mg} / \mathrm{dm}^{3}$ ), 
while for $\mathrm{FeCl}_{3}$ use this effect was not observed. These findings shed a new light on presented approaches to CAPS assessment methods available in literature [7-9]. Results of this experiment clearly indicate that the obligatory use of polyelectrolyte, as assumed in mentioned multi-criteria assessment method, may lead to false conclusions. In this case, while selecting $\mathrm{FeCl}_{3}$ as coagulant for CAPS, additional polyelectrolyte dosing makes no sense for process efficiency, unnecessarily increasing operational costs.

Table 3. Raw wastewater composition compared with conventional sedimentation efficiency.

\begin{tabular}{|c|c|c|c|c|}
\hline Name & Unit & $\begin{array}{c}\text { Raw } \\
\text { wastewater }\end{array}$ & $\begin{array}{c}\text { Wastewater after } \\
\text { sedimentation }\end{array}$ & $\begin{array}{c}\text { Sedimentation } \\
\text { effect }\end{array}$ \\
\hline $\mathrm{COD}$ & $\mathrm{mgO}_{2} / \mathrm{dm}^{3}$ & 546.00 & 352.00 & $36 \%$ \\
\hline $\mathrm{COD} 1.0 \mu \mathrm{m}$ & $\mathrm{mgO}_{2} / \mathrm{dm}^{3}$ & 149.00 & - & - \\
\hline $\mathrm{COD} 0.1 \mu \mathrm{m}$ & $\mathrm{mgO}_{2} / \mathrm{dm}^{3}$ & 142.00 & - & - \\
\hline $\mathrm{BOD}$ & $\mathrm{mgO} / \mathrm{dm}^{3}$ & 314.80 & 192.8 & $39 \%$ \\
\hline Total Phosphorus & $\mathrm{mgP} / \mathrm{dm}^{3}$ & 9.05 & 7.15 & $21 \%$ \\
\hline Phosphate & $\mathrm{mgP}-\mathrm{PO}_{4} / \mathrm{dm}^{3}$ & 5.54 & - & - \\
\hline Total Nitrogen & $\mathrm{mgN} / \mathrm{dm}^{3}$ & 97.20 & 92.00 & $5 \%$ \\
\hline Ammonia & $\mathrm{mgN}-\mathrm{NH}_{4} / \mathrm{dm}^{3}$ & 58.40 & - & - \\
\hline Nitrate & $\mathrm{mgN}-\mathrm{NO}_{3} / \mathrm{dm}^{3}$ & 0.55 & - & - \\
\hline Nitrite & $\mathrm{mgN}-\mathrm{NO}_{2} / \mathrm{dm}^{3}$ & 0.02 & - & - \\
\hline $\mathrm{pH}$ & - & 7.87 & - & - \\
\hline Alkalinity & $\mathrm{mVal} / \mathrm{dm}^{3}$ & 8.90 & - & $38 \%$ \\
\hline TSS & $\mathrm{mgTSS} / \mathrm{dm}^{3}$ & 336.00 & 142.00 & $35 \%$ \\
\hline VSS & $\mathrm{mgTSS} / \mathrm{dm}^{3}$ & 142.00 & 92.30 & - \\
\hline
\end{tabular}

In general, the best effect of COD removal was achieved for $\mathrm{AlCl}_{3}$ supported by polyelectrolyte addition (45-48\% higher than conventional sedimentation for doses over $60 \mathrm{mg} / \mathrm{dm}^{3}$ ). However, differences between COD removal efficiency at low doses (up to $20 \mathrm{mg} / \mathrm{dm}^{3}$ ) were small and for this range of desired COD removal level unit costs of substance are most relevant in overall assessment.

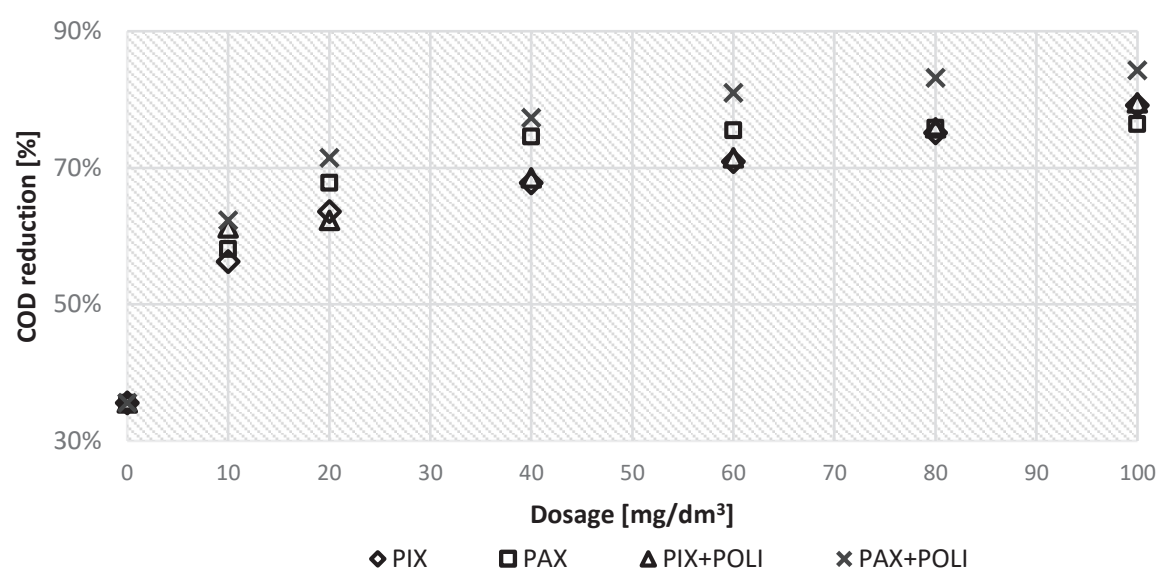

Fig. 1. COD removal efficiency achieved in series of jar tests.

Furthermore, for series where the best COD removal effect was achieved, other parameters of treated wastewater were investigated. Results are presented at Figure 2. Dose of $40 \mathrm{mg} / \mathrm{dm}^{3}$ of $\mathrm{AlCl}_{3}$ supported by $1 \mathrm{mg} / \mathrm{dm}^{3}$ of polyelectrolyte effected with complete 
removal of total phosphorus and phosphates, while doses above $10 \mathrm{mg} / \mathrm{dm}^{3}$ had no further effect on total nitrogen removal which stood at about $30 \%$.

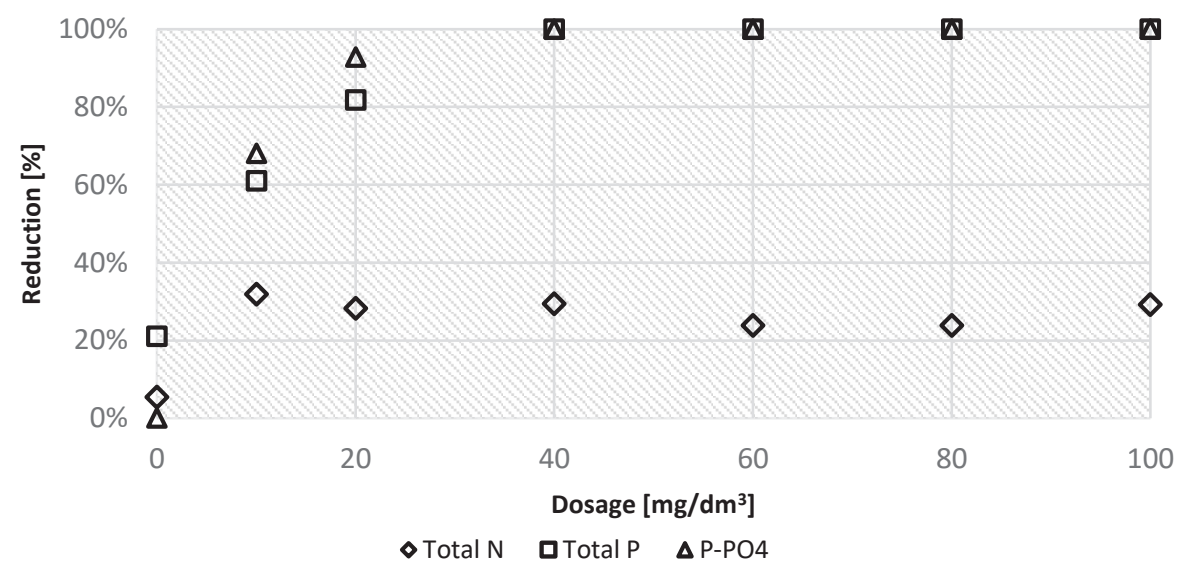

Fig. 2. Other pollutants removal efficiency obtained in PAX+POLY test series.

Table 4. Economic balance for tested CAPS variants.

\begin{tabular}{|c|c|c|c|c|c|c|}
\hline \multirow[b]{2}{*}{ Coagulant } & \multirow[b]{2}{*}{ Dose } & \multicolumn{2}{|c|}{ Cost } & \multicolumn{2}{|c|}{\begin{tabular}{|c|} 
Income \\
\end{tabular}} & \multirow[b]{2}{*}{ Balance } \\
\hline & & $\begin{array}{l}\text { sludge } \\
\text { disposal }\end{array}$ & $\begin{array}{c}\text { Chemical } \\
\text { cost }\end{array}$ & $\begin{array}{c}\text { Decrease of air } \\
\text { demand }\end{array}$ & $\begin{array}{c}\text { Renewable energy } \\
\text { production }\end{array}$ & \\
\hline- & $\mathrm{mg} / \mathrm{dm}^{3}$ & \multicolumn{5}{|c|}{$€ / 1000 \mathrm{~m}^{3}$ wastewater } \\
\hline \multirow{6}{*}{ PIX } & 10 & $0.40 €$ & $7.05 €$ & $7.98 €$ & $10.09 €$ & $10.62 €$ \\
\hline & 20 & $7.78 €$ & $14.11 €$ & $10.80 €$ & $13.67 €$ & $2.58 €$ \\
\hline & 40 & $9.87 €$ & $28.21 €$ & $12.43 €$ & $15.72 €$ & $-9.93 €$ \\
\hline & 60 & $9.80 €$ & $42.32 €$ & $13.63 €$ & $17.24 €$ & $-21.25 €$ \\
\hline & 80 & $15.30 €$ & $56.43 €$ & $15.25 €$ & $19.30 €$ & $-37.18 €$ \\
\hline & 100 & $27.65 €$ & $70.54 €$ & $16.80 €$ & $21.26 €$ & $-60.12 €$ \\
\hline \multirow{6}{*}{ PAX } & 10 & $0.67 €$ & $18.19 €$ & $8.68 €$ & $10.99 €$ & $0.81 €$ \\
\hline & 20 & $11.54 €$ & $36.39 €$ & $12.43 €$ & $15.72 €$ & $-19.78 €$ \\
\hline & 40 & $18.93 €$ & $72.78 €$ & $15.04 €$ & $19.03 €$ & $-57.64 €$ \\
\hline & 60 & $20.54 €$ & $109.16 €$ & $15.39 €$ & $19.47 €$ & $-94.83 €$ \\
\hline & 80 & $23.62 €$ & $145.55 €$ & $15.53 €$ & $19.65 €$ & $-133.99 €$ \\
\hline & 100 & $28.86 €$ & $181.94 €$ & $15.74 €$ & $19.92 €$ & $-175.13 €$ \\
\hline \multirow{6}{*}{ PIX+POLY } & 10 & $3.36 €$ & $8.04 €$ & $9.88 €$ & $12.51 €$ & $10.99 €$ \\
\hline & 20 & $5.23 €$ & $15.10 €$ & $10.31 €$ & $13.04 €$ & $3.02 €$ \\
\hline & 40 & $13.02 €$ & $29.20 €$ & $12.71 €$ & $16.08 €$ & $-13.44 €$ \\
\hline & 60 & $17.45 €$ & $43.31 €$ & $13.84 €$ & $17.51 €$ & $-29.41 €$ \\
\hline & 80 & $22.28 €$ & $57.42 €$ & $15.53 €$ & $19.65 €$ & $-44.51 €$ \\
\hline & 100 & $24.16 €$ & $71.53 €$ & $16.94 €$ & $21.44 €$ & $-57.30 €$ \\
\hline \multirow{6}{*}{ PAX+POLY } & 10 & $5.23 €$ & $19.18 €$ & $10.31 €$ & $13.04 €$ & $-1.07 €$ \\
\hline & 20 & $13.29 €$ & $37.38 €$ & $13.84 €$ & $17.51 €$ & $-19.32 €$ \\
\hline & 40 & $15.97 €$ & $73.77 €$ & $16.10 €$ & $20.37 €$ & $-53.27 €$ \\
\hline & 60 & $17.58 €$ & $110.15 €$ & $17.51 €$ & $22.15 €$ & $-88.07 €$ \\
\hline & 80 & $20.94 €$ & $146.54 €$ & $18.36 €$ & $23.23 €$ & $-125.90 €$ \\
\hline & 100 & $23.49 €$ & $182.93 €$ & $18.78 €$ & $23.76 €$ & $-163.88 €$ \\
\hline
\end{tabular}

Except technological effects investigated in series of experiments, for full CAPS assessment an economic analysis has been performed. Using methodology and values presented in Section 2.4, benefits from higher renewable energy production and lower oxygen 
consumption for organic matter mineralization were compared with costs of chemicals purchase and higher sludge production (Table 4). Only for lowest doses of ferric chloride $\left(10\right.$ and $\left.20 \mathrm{mg} / \mathrm{dm}^{3}\right)$ and the smallest dose of alum chloride, the economic balance was positive. A much lower price of $\mathrm{FeCl}_{3}$ (over 2.5 times lower than $\mathrm{AlCl}_{3}$ ) and similar treatment efficiency in this range of COD removal (64\% and $68 \%$ for $\mathrm{FeCl}_{3}$ and $\mathrm{AlCl}_{3}$, respectively) makes ferric chloride more suitable for these purposes. Higher doses of chemicals in all tests do not increase plant's energy balance as much as purchase and additional sludge disposal costs rise which makes them unfounded for these purposes.

\section{Conclusions}

- In tested range, the best COD removal effect (84\%) was achieved in series using alum chloride supported by polyelectrolyte $\left(100 \mathrm{mg} / \mathrm{dm}^{3}+1 \mathrm{mg} / \mathrm{dm}^{3}\right.$ of each substance).

- Lower doses of coagulants (up to $40 \mathrm{mg} / \mathrm{dm}^{3}$ ) in series with and without polyelectrolyte addition had similar COD removal efficiency. Differences in this parameter removal were less than $10 \%$.

- Polyelectrolyte addition had practically no impact on the ferric chloride efficiency. Addition of polyelectrolyte in series where $\mathrm{AlCl}_{3}$ was used increased COD removal very slightly $(5-6 \%)$. Such results suggest that coagulants selection and assessment methodology must include coagulant efficiency tests without polyelectrolyte addition.

- The economic assessment performed in this study suggests that CAPS can be useful for plant's energy balance at some level. However, only lower doses of selected coagulants allowed to obtain positive economic balance due to lower energy production increase along with higher chemicals costs with higher doses. However, performed analysis had a preliminary character and further calculations have to be made along with modelling studies of CAPS impact on the biological treatment efficiency.

\section{References}

1. N. Jardin, D. Thöle, B. Wett, WEF 7, 5237-5255 (2006)

2. C. Fux, H. Siegrist, Water Sci. Technol. 50, 19-26 (2016)

3. B. Wett, S. Murthy, I. Takács, M. Hell, G. Bowden, A. Deur, M. O'Shaughnessy, Pro. Water Pract. 1, 1-11 (2007)

4. S.A Olav, N. Derwort, J. Campos, M. Strous, J.G. Kuenen, M. Jetten, Water Res. 36, 2475-2482 (2002)

5. J.G. Kuenen, Nat. Rev. Microbiol. 6, 320-326 (2008)

6. G. Tchobanoglous, H.D. Stensel, R. Tsuchihashi, F.L. Burton, Wastewater Engineering: Treatment and Resource Recovery (Metcalf \& Eddy, 2003)

7. G. De Feo, S. De Gisi, M. Galasso, Desalination 230, 229-238 (2008)

8. C.S. Poon, C.W. Chu, Chemosphere 39, 1573-1582 (1999)

9. G. De Feo, S. De Gisi, M. Galasso, Green Technologies for Wastewater Treatment, 1-18 (2012) 